\title{
ADVANCED MATERIAL TECHNOLOGY FOR THE CONSERVATION OF HISTORICAL BUILDINGS
}

\author{
PARASKEVI CHANTZI ${ }^{1}$, ELISSAVET DOTSIKA ${ }^{1,2}$ \\ ${ }^{1}$ Laboratory of Stable Isotopes and Radiocarbon, Institute of Nanoscience \& Nanotechnology, \\ NCSR “Demokritos", 153 10, Greece \\ ${ }^{2}$ Institute of Geosciences and Earth Resources, Via G. Moruzzi 1, 56124 Pisa, Italy
}

\begin{abstract}
Four different compositions were designed for restoration mortars reflecting the dominant ancient and historical types. Three of them (two lime and one hydraulic lime mortar) contained a pozzolanic member while the two of them (lime and hydraulic lime mortar) contained polypropylene fibers. Micro-morphological and elemental (SEM/EDAX), mineralogical (XRD) and thermal analysis (TGA) were performed in order to identify the microstructure, the chemical consistency, and durability of each composition. Although hydraulic lime presented a slightly better response on mechanical strength, lime mortar with pozzolan and polypropylene fibers selected, in terms of cost factor, as a sufficient composition for further research. Meeting the requirements for materials under the triptych of "compatibility-coherence-reversibility" with the authentic ancient matrix as well as resistant to climate changes, metakaolin was used as an improvement agent in the binder part at $25 \%$ replacement. The experimental mortar (EM) updated its characteristics in both mechanical and hydraulic aspects. Crystallization test, elevated humidity conditions, acid rain, freeze-thaw tests were performed under simulated conditions with respect to international standards. EM mortar responded adequately to extreme climatic conditions in contrast to the standard lime mortar. That attributed to the ability of metakaolin to resist in contractionexpansion processes by maintaining its matrix.
\end{abstract}

Keywords: mortars, culture-heritage, conservation

\section{INTRODUCTION}

\section{Conservation of Historical Monuments and Buildings}

The term of conservation includes an integrated management program under which environmental variations are taken into account in projects regarding the protection of historical monuments and building. As "damage" could be defined a deterioration mechanism on mortars which becomes apparent at a certain moment affecting the physical, chemical and/or mechanical properties. The most important of damage factors are humidity, air pollution, the presence of soluble salts and organic activity (Van Hees et al., 2004; Charola, 2004). All of them are interwoven to the climate factor, therefore, the conservation materials should be considered under this aspect as well. For example, precipitation which acts in the vertical line at the buildings and enhance the capture of humidity is dependent on climate change. Moreover, precipitation factor could be attributable for the import of dissolved acidic components in the material surface (Amoroso \& Fassina, 1983). However, the triptych of "compatibility-coherencereversibility" with the authentic matrix is of major importance in the design of restoration products. With respect to above lines, an attempt was made to design conservation mortars addressing improvements in binder materials.

\section{Preparation of Standard Restoration Mortar}

Initially, four different compositions were designed for restoration mortars reflecting the dominant ancient and historical types. (Table 1). The lime/pozzolan ratio was 1:1 for D1 while for D2, D3, D4 was 1:2 considering a better reaction between lime and 
pozzolan in order to achieve more efficient hydraulic characteristics in mortars (Massazza, 1998). For the aggregates, a silica sand was used according to standard BS EN 196-1:2005 (Methods of testing cement, sand for strength measurements) as well as crushed ceramics of properly gradation for a sufficient porosity (Figure 1). The weight ratio of binder to aggregate was 1:3 as it is accomplished the development of a porous system capable of delivering elevated mechanical strength reflecting ancient mortars. Mortars were prepared in standard $40 \mathrm{~mm}$ x $40 \mathrm{~mm}$ x $160 \mathrm{~mm}$ specimens. Mortar mixers were used and attention was paid to the intensity in order not to break the aggregates. Polypropylene fibers were added in the dry blend for D3 and D4 compositions. This admixture was chosen to protect mortars against "cracking" from capillary cracks during drying and temperature variations. The required amount of water estimated based on BS EN 1015-11: 1999. By the end of mortar preparation, the triplet metal matrixes were mechanically filled as described in BS EN 196-1:2005. After 24h where specimens allowed curing they placed in a temperature chamber at $20 \pm 1^{\circ} \mathrm{C}$ and $95 \%$ humidity for 28 days. Then placed at ambient conditions with relative humidity $65 \%$ and temperature $20 \pm 1^{\circ} \mathrm{C}$ for 9 months to develop their characteristics and to remove excess moisture.

Table 1. Composition of standard conservation mortars

\begin{tabular}{cccccc}
\hline & \multicolumn{5}{c}{ Standard Mortars } \\
& Raw material & D1 & D2 & D3 & D4 \\
\hline \multirow{5}{*}{ Binder } & Lime & + & + & & + \\
& Hydraulic lime & & & + & \\
& Pozzolan & & + & + & + \\
Aggregates & Ceramic powder & + & + & + & + \\
Quartz sand & + & + & + & + \\
& crushed ceramics & + & + & + & + \\
\hline
\end{tabular}

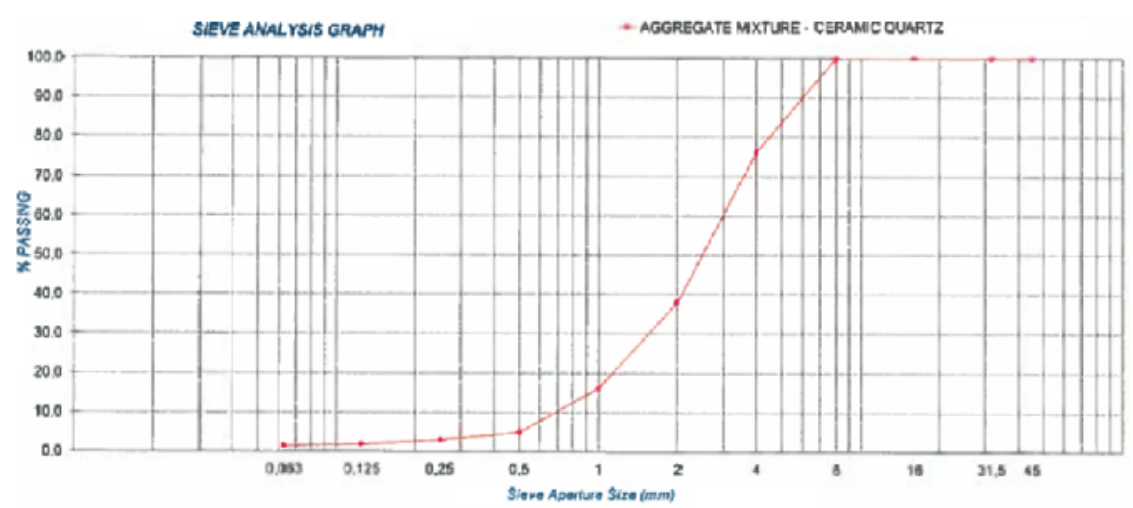

Figure 1. Grading curve of the aggregate in standard mortars

\section{MATERIALS AND METHODS}

SEM/EDAX methods were used to determine the morphological and elemental characteristics of mortars. Photomicrographs were selected with secondary and 
ICAMS $2016-6^{\text {th }}$ International Conference on Advanced Materials and Systems

backscattered electron detector. Elemental analysis was performed by sequential scanning of an electron beam on the sample surface while mineralogical analysis conducted with X-ray diffraction (XRD). Mechanical properties related to flexural strength were measured according to BS EN 1015-11: 1999.
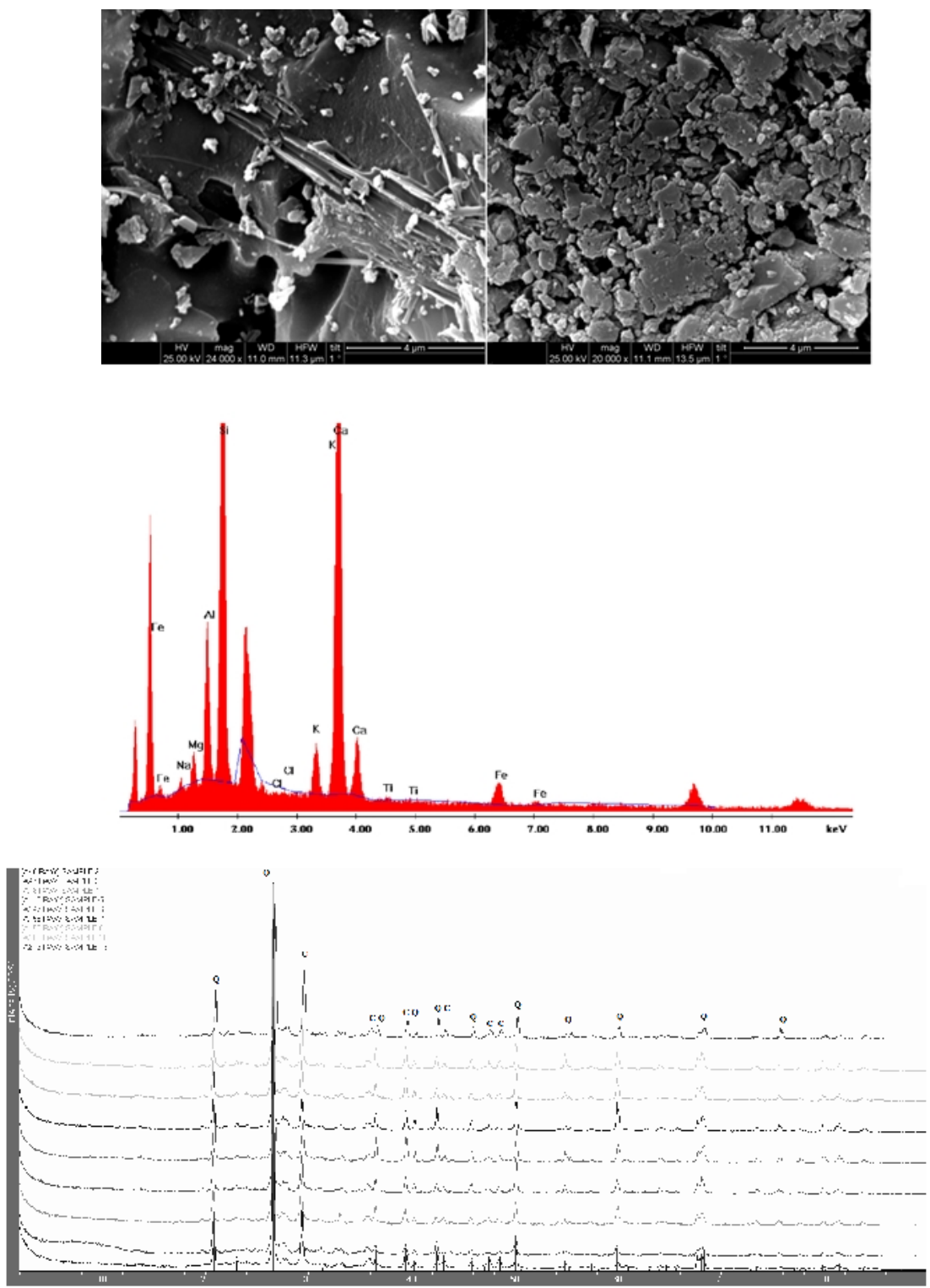

Figure 2. Morphological, chemical and mineralogical [Q-quartz; C-calcite] analysis in standard mortars 


\section{RESULTS AND DISCUSSION}

Chemical analyses concluded on a high concentration of pozzolanic oxides $\left(\mathrm{SiO}_{2}\right.$ : $48 \%-60 \%$ and $\mathrm{Al}_{2} \mathrm{O}_{3}: 10 \%-18 \%$ ) which were homogenized distributed. Calciumsilicate and calcium-aluminate oxides presented a linear relationship inversely related highlighting the formation of $\mathrm{C}-\mathrm{S}-\mathrm{H}$ and $\mathrm{C}-\mathrm{A}-\mathrm{H}$ active hydrated phases. This observation comes in agreement with the XRD qualitative characterization where quartz (Q) and calcite (C) minerals (Figure 2) mainly detected. Generally, the carbonation reaction in lime mortars with pozzolanic additives (D2, D3, D4) presented sufficient mechanical strength values with a median range of development. D4 sample presented the smaller flexural strength $(0.9 \mathrm{MPa})$ and the higher total porosity $(39 \%)$ in 94 days of maturation however was greatly improved in 289 days (1.8MPa fl.st. and $33 \%$ t.p.). The best respond was for D3 sample from the start (1.4MPa fl.st. and 31\% t.p. in 94 days) as well as at the conclusion (1.9MPa fl.st. and 27\% t.p. in 289 days) of the experiment. D1 and D2 samples exhibited lower values characterized as sufficient. D1 sample, despite the absence of pozzolanic member, exhibits excellent strength values 1.0MPa in 94 days of maturation and $1.7 \mathrm{MPa}$ in 289 days (better that D2) indicating the ceramic powder as a valuable technical pozzolan in mortars. Finally, samples D3 and D4 became more resistible to "cracking episodes" as developed the higher strengths due to polypropylene fibers. Although D3 hydraulic mortar presented better characteristic than D4 lime mortar considering the higher cost as deterrent factor, D4 sample was chosen for further improvements.

\section{Improvements on Standard Mortars}

The rule under which the decision for the improvement agent was made based on the impact of climatic effects as deterioration factors. One of the main damages in historical monuments and building is the formation of plaster due to sulfates, especially in urban or industrial centers where air pollution is evident (Hossack and Thomas, 2015; Santhanam et al., 2002). Moreover, taking into account the climate change where the temperature rises and drying cycles become more intense (Lelieveld et al., 2012; IPCC, 2007) the design imposed the enhancement of resistance in cracking mechanisms during the maturation and strengthen period for the mortars, further than that imparted by polypropylene fibers. Attending to address the above parameters metakaolin (MK) was used in the binder part at $25 \%$ replacement. Moreover, it has been reported the increased resistance to sulfate attack with MK replacement (Wu et al., 2016; Nabil, 2006). The evaluation of the experimental mortar EM was based on hydraulicity, as expressed by $\mathrm{CO}_{2} / \mathrm{H}_{2} \mathrm{O}$ ratio, and mechanical strength. The hydraulicity was estimated with Thermal Gravimetric Analysis (TGA). The weight loss measured between $200-600^{\circ} \mathrm{C}$ and over $600^{\circ} \mathrm{C}$. The range of $200-600^{\circ} \mathrm{C}$ represents the structural bound water which released with the dissolution of aluminosilicate bonds while the weight loss over $600^{\circ} \mathrm{C}$ represents the dissolution of $\mathrm{CO}_{2}$ bonds (Frankeová et al., 2012). "Recarbonated" material was not detected resulting in reliable hydraulicity ratios. Flexural strength versus $\mathrm{CO}_{2} / \mathrm{H}_{2} \mathrm{O}$ ratio diagram (Figure 3) was constructed to standard and experimental mortars. Moreover, literature data were added (Frankeová et al., 2012). 
ICAMS $2016-6^{\text {th }}$ International Conference on Advanced Materials and Systems

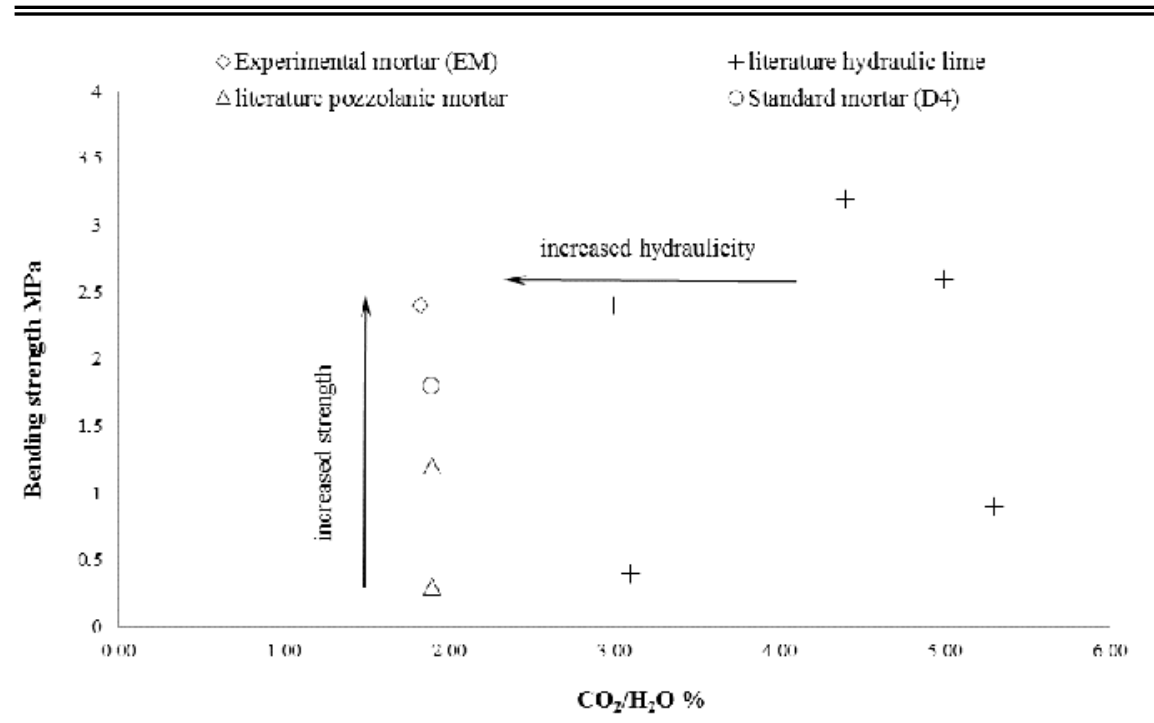

Figure 3. Flexural strength versus $\mathrm{CO}_{2} / \mathrm{H}_{2} \mathrm{O}$ ratio [literature data Frankeová et al., 2012]

The development of flexural strength increased in experimental mortar with respect to the standard mortar D4. Metakaolin, as presents large specific surface area and high pozzolanic factor, enhanced the initial mortar with a positive effect on microstructure (total porosity for EM 29\% and for D4 33\%) as well. Furthermore, it is observed that structurally bound water exhibited a higher ratio in EM sample (4.1\%) than D4 sample (3.6\%) suggesting the improvement of the pozzolanic activity in experimental mortal. In figure 3 it is evident that both EM and D4 samples grouped in the vertical axis with the pozzolanic samples, a binder of high hydraulicity, while in horizontal axis EM grouped with the hydraulic mortars presenting higher flexural strength than D4. This observation leads to the conclusion that the choice of MK as improvement agent gained the benefits regarding both mechanical and hydraulic aspects.

Finally, EM and D4 samples were tested in experimental environmental conditions. Many tests were run in order to detect the response of mortars under extreme condition. Crystallization test, elevated humidity conditions, acid rain, freeze-thaw tests were performed under simulated conditions with respect to international standards e.g. EN 12370 (1999), in order to detect the adequate response of EM sample. In more detail, variations in the weight of the samples were relatively small regarding crystallization and elevated humidity tests. However, in elevated humidity conditions, EM presented a better response with increased flexural strength until the second cycle. This is consistence with hydro-thermal TGA analysis where the enhanced pozzolanic properties were detected. The simulation of acid rain evaluated with three damage indicators DMC, DCC and DEC, concerning mass loss ratio, compressive strength variation, and variation of modulus of elasticity, respectively. Samples showed a constant rate of mass loss when exposed to acid solutions which increased gradually with increasing soak time. At the same time the strength gradually decreases with a total failure behavior at the $\mathrm{pH} 1.5$ solution. Modulus of elasticity presented higher variations over 35 days in $\mathrm{pH} 1.5$ solution and over 45 days in $\mathrm{pH}$ 2.5-3.5 solutions. In 
freeze-thaw tests, EM responded well enough without any failures, unlike D4 where the reduction of their strength was more pronounced when the porosity increased.

\section{CONCLUSIONS}

Four different compositions were designed for restoration mortars reflecting the dominant ancient and historical types. Micro-morphological and elemental (SEM/EDAX), mineralogical (XRD) and thermal analysis (TGA) were performed in order to identify the microstructure, the chemical consistency and durability of each composition. Lime mortar with pozzolan and polypropylene fibers selected in terms of cost factor as a sufficient composition for further investigation. Attending to address enhanced cracking mechanisms due to climate variations, metakaolin (MK) was used in the binder part at $25 \%$ replacement. Experimental mortar (EM) updated its characteristics in both mechanical and hydraulic aspects. Moreover, EM responded well enough to crystallization test, elevated humidity conditions, acid rain, freeze-thaw tests. The success of EM lies in the ability of metakaolin to resist in contractionexpansion processes by maintaining its matrix as produce strong bonds preventing the generation of large porous.

\section{REFERENCES}

Amoroso, G. and Fassina, V. (1983), "Stone Decay and Conservation”, Materials Science Monographs, 11, Elsevier Science, Amsterdam.

BS EN 196-1:2005. Methods of Testing Cement. Determination of Strength. British Standards Institute: London, UK, 2005.

BS EN 1015-11: 1999. Methods of test for mortar for masonry. Determination of flexural and compressive strength of hardened mortar. British Standards Institution: London 1999.

Charola, A. (2004), "Stone Deterioration in Historic Building and Monuments", 10th International Congress on Deterioration and Conservation of Stone, Stockholm, Sweden, 3-14.

EN 12370:1999. Natural stone test methods-determination of resistance to salt crystallization, 1999-2003.

Frankeová, D., Slížková, Z., Drdácký, M. (2012), "Characteristics of mortars from ancient bridges”, in Válek, J., Hughes, J.J., Groot, C.J.W.P. (eds.), Historic Mortars: Characterisation, Assessment and Repair, vol. 7, $165-74$

Hossack, A.M. and Thomas, M.D.A. (2015), "The effect of temperature on the rate of sulfate attack of Portland cement blended mortars in $\mathrm{Na}_{2} \mathrm{SO}_{4}$ solution", Cement and Concrete Research, 73, 136-142.

IPCC (2007), Climate Change 2007: The Physical Science Basis. Contribution of Working Group I to the Fourth Assessment Report of the Intergovernmental Panel on Climate Change, Solomon, S. et al. (eds.), Cambridge University Press, Cambridge, UK.

Lelieveld, J., Hadjinicolaou, P., Kostopoulou, E. et al. (2012), Climatic Change, 114: 667, doi:10.1007/s10584-012-0418-4.

Nabil, M.A. (2006), "Durability of metakaolin concrete to sulfate attack," Cement and Concrete Research, 36, 1727-1734.

Santhanam, M., Cohen, M.D. and Olek, J. (2002), "Mechanism of sulfate attack: a fresh look. Part 1: summary of experimental results", Cement and Concrete Research, 32(6), 915-921.

Van Hees, J., Binda, L., Papayianni, I. and Toumbakari, E. (2004), "Characterisation and Damage Analysis of Old Mortars", Materials and Structure, 37, 644-648.

Wu, Z., Deng, Y., Liu, S., Liu, Q., Chen, Y., Zha, F. (2016), "Strength and micro-structure evolution of compacted soils modified by admixtures of cement and metakaolin", Applied Clay Science, Volumes 127-128, Pages 44-51. 